\title{
Alien conifer invasions in South America: short fuse burning?
}

\author{
David M. Richardson - Brian W. van Wilgen • \\ Martin A. Nuñez
}

Received: 15 June 2007 / Accepted: 3 July 2007 / Published online: 25 July 2007

(C) Springer Science+Business Media B.V. 2007

\begin{abstract}
Alien conifers have been widely planted in the Southern Hemisphere. Australia, New Zealand and South Africa, all with long histories of alien conifer planting, have major problems with invasive conifers ("wildings"). Widespread planting of alien conifers has a much shorter history in South America, and invasions are a recent phenomenon. A workshop was convened in Argentina in May 2007 to discuss the rapid emergence of problems with invasive conifers in South America. Workshop delegates agreed that: the problem is likely to increase substantially and rapidly in many parts of the continent; the problem is not widely recognized; lessons from elsewhere can be transferred; and
\end{abstract}

Electronic supplementary material The online version of this article (doi:10.1007/s10530-007-9140-y) contains supplementary material, which is available to authorized users.

D. M. Richardson ( $\square)$

Centre for Invasion Biology, Department of Botany and Zoology, Stellenbosch University, Private Bag X1, Matieland 7602, South Africa

e-mail: rich@sun.ac.za

B. W. van Wilgen

Centre for Invasion Biology, CSIR Natural Resources and the Environment, P.O. Box 320, Stellenbosch 7599, South Africa

M. A. Nuñez

Department of Ecology and Evolutionary Biology, University of Tennessee, 569 Dabney Hall, Knoxville, TN 37996, USA collaboration can bring benefits. The need was expressed: for an accurate assessment of the dimensions of the problem; to raise awareness of the problem; for a common research agenda; to initiate management interventions. This paper summarizes the key aims, deliberations, and planned outcomes of the workshop.

Keywords Biological invasions - exotic plants · Pinus · Trees · Management - Pseudotsuga

Conifers have been planted outside their natural range in many parts of the world for hundreds of years, and for a range of reasons, but most importantly as a basis for commercial forestry. Plantations of alien conifers are now very widespread in many parts of the world, especially in Australia, New Zealand, and southern Africa, where they now make up a significant part of commercial forestry operations. In South America, the practice of widespread planting of alien conifers is comparatively recent, but is rapidly becoming a significant form of land use.

The invasive spread of alien conifers was first noted in South Africa in 1855, in New Zealand between 1880 and 1900, and in Australia in the 1950s. Since then, invasive conifers (and pines, genus Pinus, in particular) have increased to become a major environmental issue, invading thousands of hectares, notably in South Africa and New Zealand. There is a long history of research and management 
of alien conifer invasions in these regions. As a result, now there is a considerable body of research on the ecology of alien conifer invasions, especially pines. This is based largely on empirical evidence from South Africa, New Zealand, and Australia (Richardson and Higgins 1998). In each of these regions, a range of management strategies and interventions aimed at addressing the problem of invasions have been developed and tested. These include the introduction of deliberate policies for the management of invasive species, backed by legislation, and the development and implementation of programs of mechanical control, landscape management, and altered silvicultural practices. Although the evolution of strategies followed very different trajectories in different regions due to environmental factors and historical, cultural, and socio-political issues, there is an acute awareness of these problems amongst foresters, conservationists and even the public at large.

As a result of recent widespread afforestation programs and other plantings, alien conifer invasions are now beginning to emerge as a problem in several parts of South America (Richardson and Rejmánek 2004; Fig. 1). Invasions are already evident in many regions, and the problem is poised to grow very rapidly in next few decades. This prediction arises from the fact that many of the extensive plantations are yet to reach seed-bearing age, while in other areas the new invasions have not yet reached the phase of exponential growth.

Considerable experience, gained over the past century, in the management of conifer invasions in the southern hemisphere provides the opportunity to transfer learning and experience to South America. With this in mind, 15 researchers from Argentina, Brazil, Chile, New Zealand, South Africa and the USA assembled for a 3-day workshop on Isla Victoria near Bariloche, Argentina $(10-12$ May 2007) to discuss the many facets of the issue. The workshop brought together considerable experience on the ecology and management of conifers, as native trees, plantation crops and as invasive alien species. The workshop had three goals:

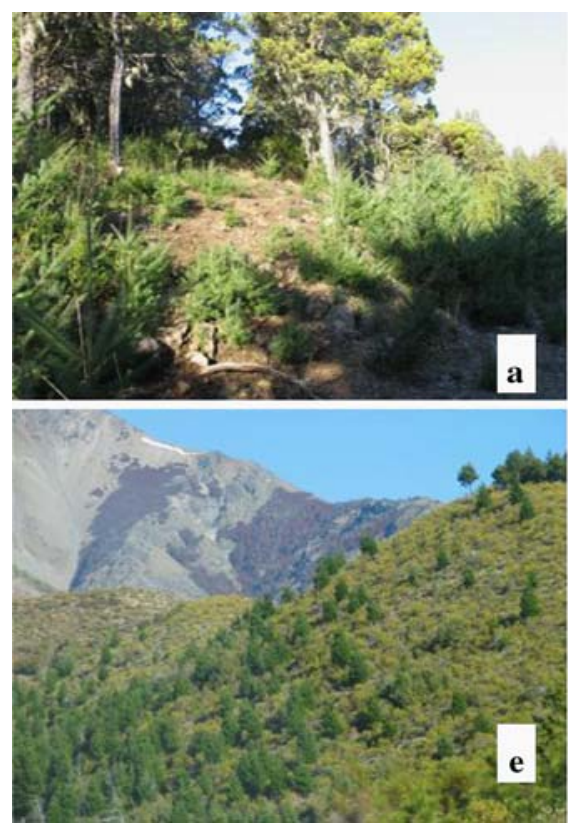

Fig. 1 A selection of invasive alien conifers in Patagonia, Argentina, observed during the pre-workshop excursion between Bariloche (Río Negro province) and Esquel (Chubut province). (a) Pseudotsuga menziesii (Douglas-fir) near Trevelin, Chubut; (b) Pinus contorta spreading from roadside plantings near Bariloche airport; (c) Pinus ponderosa and

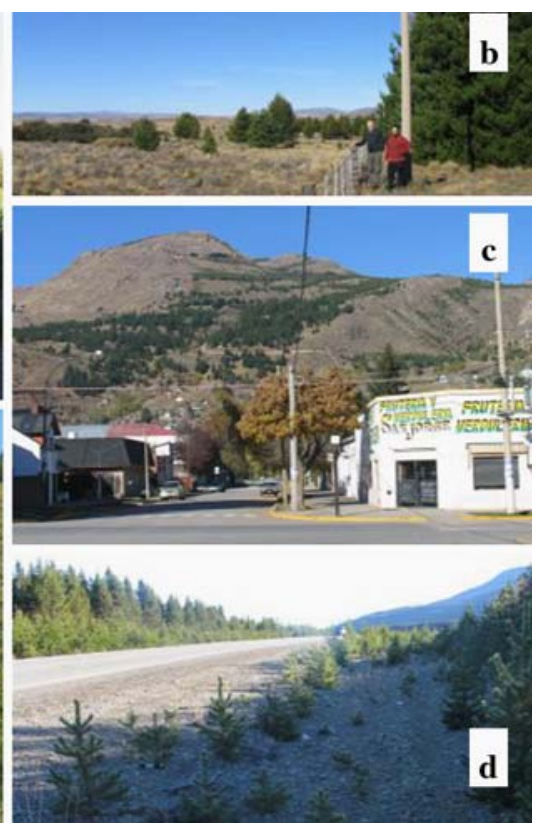

$P$. radiata plantations on the outskirts of Esquel. Plantings such as this serve as foci for invasions. (d) Prolific natural regeneration of $P$. contorta subsp. murrayana (Sierra Nevada lodgepole pine) near El Bolson, Río Negro; (e) Widespread $P$. ponderosa invasions between Bariloche and El Bolson, Río Negro 
a. To assess the problem of conifer invasions on the South American continent, and to look for parallels from other southern hemisphere regions that could be used to predict likely outcomes in South America;

b. To share learning, both between practitioners and researchers from South America, as well as between South Americans and other southern hemisphere ecologists, with a view to capacitybuilding; and

c. To provide information on the problem, and potential solutions, for use by policy-makers and managers.

The workshop followed a format of formal presentations from the represented regions, followed by a series of participative discussions aimed at generating outputs. At the conclusion of the workshop, the participants were asked to list their main impressions. These included:

1. That the problem is expected to increase substantially soon, in many parts of the continent. The workshop identified two important differences between the current South American situation and the historic emergence of conifer invasion problems elsewhere in the southern hemisphere. The first relates to the scale of planting. In other southern hemisphere regions, plantings were done relatively gradually over a century or more. Plantings often (but not always) involved small numbers of trees over small areas. In South America, plantings have taken place very recently, and on a continental scale that is orders of magnitude larger than early introductions elsewhere. The second difference relates to the environment. In other southern hemisphere regions, initial plantings took place in relatively undisturbed and undeveloped landscapes. In South America, plantings are taking place in a highly modified and globalized environment. This includes welldeveloped transport networks and trade links, and considerable habitat transformation, fragmentation and disturbance. Both of these differences imply that invasions will manifest themselves much faster, and on a larger scale, than was the experience elsewhere. This underscored the imperative for rapid action to avert potentially large negative impacts.
2. That the problem is not widely recognized. The presence of invasive pines is scarcely recognized in South America (Pauchard et al. 2004). There are a variety of aspects to this problem. In many areas, pines are considered to provide solutions to environmental problems (for example, soil erosion), rather than being a source of further problems. In other areas, for example Brazil, the substitution of native forests with pine plantations may be a bigger conservation problem than invasions. This is further exacerbated by regulations that do not allow for the planting and subsequent harvesting of indigenous trees, which effectively encourages the replacement of native forests with plantations of invasive conifers. In Argentina, plantations of exotic trees are strongly promoted by the government through economic incentives. Government subsidizes up to $80 \%$ of the total cost of the plantings, with no requirements to control the natural regeneration that follows (SAGPyA 1999). Similar incentives are offered in Chile. The workshop provided an important opportunity to develop a consensus statement on the problem of alien conifer plantings, which will be used to raise awareness of the problem amongst land managers in the region ("The Bariloche Declaration"; online appendix [ESM]).

3. That lessons from elsewhere can be transferred. The workshop provided an important learning opportunity, at which participants were exposed to a range of experiences from abroad. It also provided a first opportunity for sharing experience and views between different South American countries. Participants agreed that, with caveats, much of understanding of conifer invasions (e.g. Richardson 2006), and many of the approaches to the management of conifer invasions developed elsewhere would find useful application in South America. There was agreement that this could potentially save considerable time and expense in the development of local solutions to the problem.

4. That collaboration can bring benefits. Workshop participants agreed to collaborate in the development and publication of a number of research papers addressing the topic (see below). The initiation of these collaborative projects was recognized as an important means of fostering 
interaction, with obvious benefits for learning, capacity-building, the identification of research needs and the generation of solutions. The natural experiment of plantings elsewhere in the southern hemisphere will prove very useful for predicting, for example, rates of invasion, which habitats are most likely to be invaded, types and magnitudes of impacts likely to eventuate.

At the conclusion of the workshop, participants were also asked to list what they saw as priority actions. This process resulted in the identification of four priorities:

1. The need for an accurate assessment of the dimensions of the problem. This should include the extent and distribution of plantings and invasions across the whole South American continent. Such an assessment should include, if at all possible, an assessment of the current and potential future costs and benefits of plantings to facilitate risk assessments as well as to guide the development of policy.

2. The need to raise awareness of the problem. This need was seen as urgent, especially with regard to government forestry agencies. The dissemination of information in forms other than scientific publications was seen as important in this regard.

3. The need for a common research agenda. The workshop proposed the development of such an agenda, and the establishment of a program of research, based on international collaboration. The research agenda should address, among other things, standards for data collection to facilitate continental-scale comparisons; the development of a sound ecological understanding of conifer invasions and their consequences; the development of alternatives to invasive alien conifers, including native species and sterile varieties; the potential use of biological control; and international comparative studies to derive general principles.

4. The need to initiate management interventions. Given that the problem of invasions is predicted to develop rapidly, participants considered the need to intervene through management sooner rather than later as very important. Management interventions should build on the approaches developed elsewhere. For example, the South African approach that categorizes species into groups that require different management approaches (Nel et al. 2004). The identification of priority areas for conservation, with a view to excluding the planting of certain categories of alien conifers in particular areas (Rouget et al. 2002) could also be considered. In New Zealand, the set of common-sense guidelines proposed to reduce problems with unwanted natural regeneration from plantations (Ledgard and Langer 1999) could certainly be applied in South America.

The workshop participants agreed to produce two reports, with a view to publication in the scientific literature. The first of these (with a working title of "Biogeography and ecology of introduced conifers in South America: status, impacts and prospects for invasion") would report on an eco-regional assessment of the extent of planting and the degree of invasion, and assess the potential impacts on key ecosystem services and processes. These would include hydrology, biodiversity, fire, grazing, tourism, and erosion, and would be based on best understanding of impacts elsewhere in the world. The exercise will attempt to review the importance of key ecosystem drivers (such as fire, herbivory; and site management approaches) that will direct the future invasion processes. It will also assess what research should be undertaken to best improve understanding. A key challenge in this exercise will be to obtain data on the extent of plantings of various alien conifer species in the different ecoregions of South America.

The second report (with a working title of "Conifer invasions in South America: Management challenges and solutions") will build on the ecoregional assessment, and will stress the expectation that invasions will take off much sooner, and at a larger scale, than they did on other continents, and what the expected consequences would be. The extent to which this is being addressed (or not) in South America will be reviewed, and compared to approaches to the problem in South Africa, New Zealand and Australia, with a view to identifying potential policy and management solutions and synergies at national, regional and local scales. We expect that this exercise will provide participants with enough understanding to be able to engage with stakeholders about the implementation of these proposed solutions. 
Other outcomes of the workshop included the formation of the Southern Hemisphere Network on Conifer Invasions (SHNCI; http://www.proflor.com.br/conifer_invasions/) which aims to promote interaction and collaboration between researchers, managers and planners involved in all aspects of conifer invasions in the southern hemisphere. The network plans to convene further workshops associated with various conferences, including Southern Connections, MEDECOS and EMAPI (Ecology and Management of Alien Plant Invasions), to promote the exchange of researchers and students, and to initiate engagement with a wide range of key stakeholders.

Acknowledgments We thank workshop participants R. Bustamante (Chile), S. Castro (Chile), N.J. Ledgard (New Zealand), A. Pauchard (Chile), E. Peña (Chile), E. Raffaele (Argentina) M. A. Relva (Argentina), M. Sarasola (Argentina). D. Simberloff (USA) S. M. Zalba (Argentina), R. Zenni (Brazil), and S. Ziller (Brazil) for their inputs into the identification of impressions and priorities for action. The workshop was a joint initiative of the Universidad Nacional del Comahue, Bariloche, Argentina; the Institute for Biological Invasions, University of Tennessee, USA; and the DST-NRF Centre of Excellence for Invasion Biology, South Africa.

\section{References}

Ledgard NJ, Langer ER (1999) Wilding prevention. Guidelines for minimising the risk of unwanted wilding spread from new plantings of introduced conifers. New Zealand Forest Research Institute Limited, Christchurch, New Zealand
Nel JL, Richardson DM, Rouget M, Mgidi T, Mdzeke N, Le Maitre DC, van Wilgen BW, Schonegevel L, Henderson L, Neser S (2004) A proposed classification of invasive alien plant species in South Africa: towards prioritising species and areas for management action. S Afr J Sci 100:53-64

Pauchard A, Cavieres L, Bustamante R, Becerra P, Rapoport E (2004) Increasing the understanding of plant invasions in southern South America: first symposium on alien plant invasions in Chile. Biol Invasions 6:255-257

Richardson DM (2006) Pinus: a model group for unlocking the secrets of alien plant invasions? Preslia 78:375-388

Richardson DM, Higgins SI (1998) Pines as invaders in the southern hemisphere. In: Richardson DM (ed) Ecology and biogeography of Pinus. Cambridge University Press, pp 450-474

Richardson DM, Rejmánek M (2004) Invasive conifers: a global survey and predictive framework. Diversity Distrib 10:321-331

Rouget M, Richardson DM, Nel JA, van Wilgen BW (2002) Commercially-important trees as invasive aliens-towards spatially explicit risk assessment at a national scale. Biol Invasions 4:397-412

SAGPyA (1999) Argentina, oportunidades de Inversión en Bosques Cultivados. Secretaría de Agricultura, Ganadería, Pesca y Alimentación, Buenos Aires 